\title{
Pulmonary puzzle
}

\section{Pulmonary and cutaneous nodules in an immunocompromised patient}

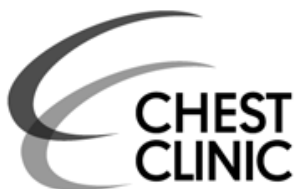

\section{CLINICAL PRESENTATION}

A 74-year-old man was admitted to hospital due to dyspnoea, malaise and purple, plaque-like papular nodules on his hands (figure 1A), soles (figure 1B) and genitalia for a duration of 1 month. He reported a 5-month history of systemic corticosteroid use for treatment of giant cell arteritis. Laboratory tests disclosed severe lymphopenia and hypogammaglobulinaemia. Pancultures and serological tests were negative, including repeated HIV serology. Contrast-enhanced CT of the chest $(2.5 \mathrm{~mm}$ slice thickness) demonstrated multiple bilateral solid pulmonary nodules with peribronchovascular distribution and a cavitating nodule in the left lower lobe (figure 1C). Abdominal CT revealed multiple hepatic ring-enhancing lesions (figure 1D). A bronchoscopy for inspection, bronchoalveolar lavage and transbronchial biopsies was discussed but deemed difficult to be performed safely due to the worsening respiratory status of the patient.

\section{QUESTION}

What is the diagnosis?

See page 1108 for the answer

\section{Panagiotis J Vlachostergios, ${ }^{1,2}$ Spiros Karamagkiolis, ${ }^{1}$ Konstantinos Karamitsos}

${ }^{1}$ Department of Internal Medicine, General Hospital of Larissa, Larissa, Greece; ${ }^{2}$ Department of Medical Oncology, University Hospital of Larissa, University of Thessaly School of Medicine, Larissa, Greece

Correspondence to Dr Panagiotis J Vlachostergios, Department of Medical Oncology, University Hospital of Larissa, University of Thessaly School of Medicine, Biopolis 41110, Larissa, Greece; pvlacho@med.uth.gr

\section{Competing interests None}

Contributors PJV and SK treated the patient and drafted the article. KK critically revised the manuscript.

Provenance and peer review Not commissioned; externally peer reviewed.

Published Online First 6 October 2011

Thorax 2011;66:1103. doi:10.1136/thoraxjnl-2011-200757
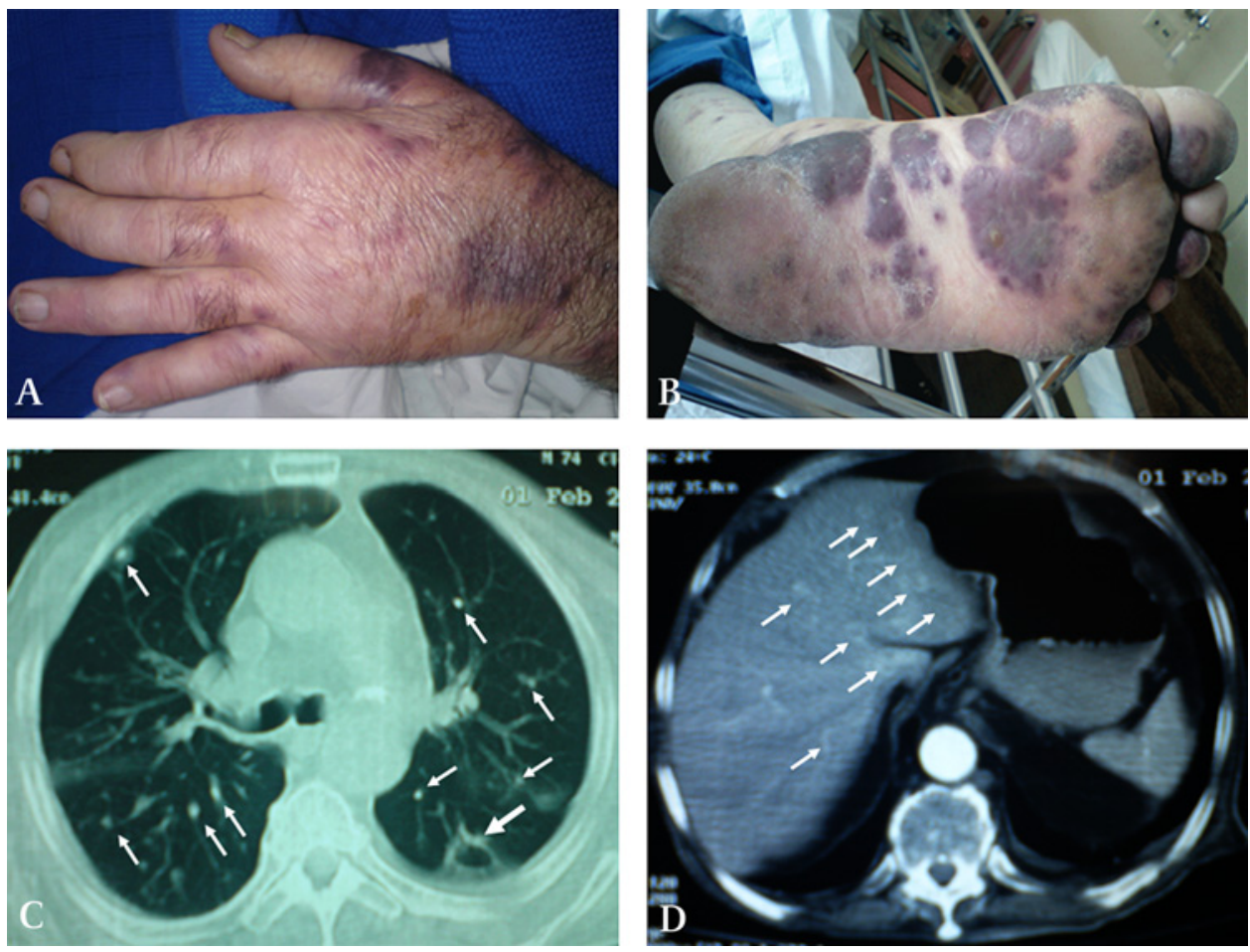

Figure 1 Papules and nodules on hands (A) and soles (B). (C) Chest CT scan showing multiple bilateral solid pulmonary nodules with peribronchovascular distribution and a cavitating nodule in the left lower lobe. (D) Abdominal CT scan showing multiple hepatic ring-enhancing lesions. 
Contributors BSQ wrote a portion of this work and revised and reviewed this work. CHG wrote the other portion of this work and revised and reviewed this work.

Provenance and peer review Not commissioned; internally peer reviewed

\section{REFERENCES}

1. Closing the Quality Gap: Revisiting the State of the Science Series: Quality Improvement Interventions to Address Health Disparities. Review Protocol. Rockville, MD: Agency for Healthcare Research and Quality, 2011. http://www.ahrq.gov/clinic/ tp/gapdisptp.htm.

2. Headrick LA, Neuhauser D. Quality health care. JAMA 1994;271:1711-12.

3. Cystic Fibrosis Foundation Patient Registry. 2009 Annual Data Report. Bethesda, Maryland: Cystic Fibrosis Foundation, 2011. http://www.cff.org/research/ ClinicalResearch/PatientRegistryReport.
4. Goss CH, Mayer-Hamblett N, Kronmal RA, et al. The cystic fibrosis therapeutics development network (CF TDN): a paradigm of a clinical trials network for genetic and orphan diseases. Adv Drug Deliv Rev 2002;54:1505-28.

5. Warwick WJ, Pogue RE. Cystic fibrosis. An expanding challenge for internal medicine. JAMA 1977;238:2159-62.

6. Batalden PB, Davidoff F. What is "quality improvement" and how can it transform healthcare? Qual Saf Health Care 2007:16:2-3.

7. Improvement Methods: Getting Started. 2011. Cambridge, MA: Institute for Healthcare Improvement. http://www.ihi.org//HI/Topics/Improvement/ImprovementMethods/ (accessed 23 Jun 2011)

8. Quinton HB, O'Connor GT. Current issues in quality improvement in cystic fibrosis. Clin Chest Med 2007:28:459-72.

9. Cystic Fibrosis Center News. Chicago, IL: Children's Memorial Hospital, 2004; Volume 10. http://www.childrensmemorial.org/documents/ cfcnews winter04.pdf.

\section{Pulmonary puzzle}

\section{ANSWER}

From the question on page 1103

A CT-guided percutaneous core needle biopsy of the left lower lobe cavitary nodule and a skin biopsy were performed. Pathological findings in both cases showed spindle-shaped cells with vascular channels (figure $2 \mathrm{~A}$ ) positive for human herpes virus 8 immunostaining (figure 2B). A final diagnosis of Kaposi's sarcoma (KS) was established, in the absence of positive cultures and stains for bacteria, fungi, protozoa, viruses or tumour cells from aspirated content of the cavitary lesion. The patient rapidly deteriorated and died.

Multiple pulmonary nodules with focal cavitary lesions may represent neoplasms such as bronchogenic carcinomas and lymphomas, or benign lesions including many types of infections or abscesses, immunological disorders such as Wegener granulomatosis and rheumatoid nodules, septic emboli, pulmonary infarcts, progressive massive fibrosis with pneumoconiosis, lymphocytic interstitial pneumonia, localised bronchiectasis and some congenital lesions. ${ }^{1}$

Intrathoracic KS, often in the context of AIDS, presents as nodular masses, with characteristic thickening of bronchovascular pathways, often accompanied by pleural effusions. ${ }^{2}$ Cavitation after necrosis of larger nodules is uncommon ${ }^{3}$ and should be associated with KS only after other causes, particularly infection, have been ruled out, as in this case. KS should not be thought of as exclusively associated with HIV infection. The emergence of $\mathrm{KS}$ in non-HIV persons is a rare but existent clinical condition, involving classic Mediterranean, endemic African and the iatrogenic form in patients on immunosuppressive medications ${ }^{4}$ as in this case. Corticosteroid immunosuppression can be significant even at moderate doses, as evidenced in this case and a previous report of non-HIV KS in an old person with giant cell arteritis. ${ }^{5}$

Thorax 2011;66:1108. doi:10.1136/thoraxinl-2011-200757

\section{REFERENCES}

1. Ryu JH, Swensen SJ. Cystic and cavitary lung diseases: focal and diffuse. Mayo Clin Proc 2003;78:744-52.

2. Khalil AM, Carette MF, Cadranel JL, et al. Intrathoracic Kaposi's sarcoma. CT findings. Chest 1995;108:1622-6.

3. Lai KK. Pulmonary Kaposi's sarcoma presenting as diffuse reticular nodular infiltrates with cavitary lesions. South Med J 1990;83:1096-8.

4. Hiatt KM, Nelson AM, Lichy JH, et al. Classic Kaposi Sarcoma in the United States over the last two decades: a clinicopathologic and molecular study of 438 non-HIVrelated Kaposi Sarcoma patients with comparison to HIV-related Kaposi Sarcoma. Mod Pathol 2008:21:572-82.

5. Kuttikat A, Joshi A, Saeed I, et al. Kaposi sarcoma in a patient with giant cell arteritis. Dermatol Online J 2006;12:16.
Figure 2 High-power photomicrographs of left lower lobe cavitary nodule, showing spindle-shaped cells with vascular channels $(A)$ and positive nuclear immunoreactivity for HHV-8 stain (B). HHV, human herpes virus.
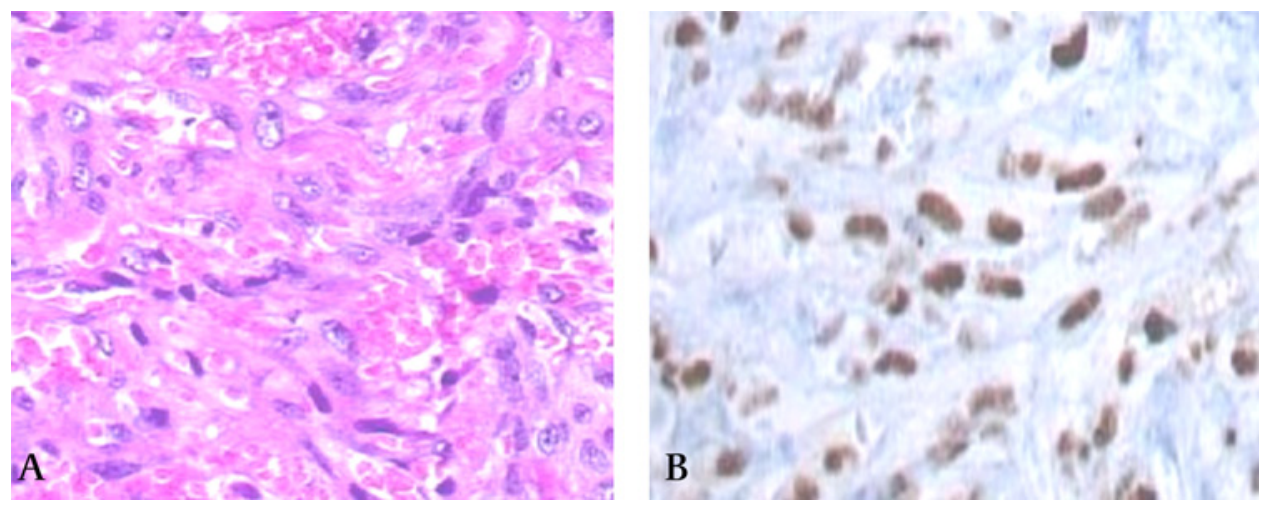